\title{
Integrative emergence in contrast to separating modularity in plant biology: views on systems biology with information, signals and memory at scalar levels from molecules to the biosphere
}

\author{
Ulrich Lüttge $\mathbb{B}$
}

Received: 19 January 2021 / Accepted: 9 February 2021/Published online: 27 February 2021

(C) The Author(s) 2021

\begin{abstract}
Modularity is reductionism and materialism, where modules are considered as building blocks per se. By contrast self-organization of modules in living organisms, like plants, generates the emergence of integrated systems with new properties not predicted by the properties of the modules. This can occur at the hierarchy of a series of scalar levels, where emergent systems become modules for emergence of new systems on the next higher scalar level akin to a hierarchy of networks from molecules, cells and individuals up to the levels of ecosystems, biomes and the entire biosphere or Gaia. The systems on these levels are holobiont-like systems, i.e., central organisms in interaction with all their associated organisms as a unit for selection in evolution. Systems biology, now a modern aspect of plant biology, has started with the advancement of whole-plant physiology in the early 1970s unraveling the roles of signaling for integration and cooperation of parts or modules in the performance of entire plants. Fixation of information in plant memory and emergence from such storage rules the timing of events of emergence. With the enthusiasm promoted by the creative self-organization of modules into the emergence of exciting new systems, biology diverts from the reductionism and materialism of bare modularity. Understanding
\end{abstract}

U. Lüttge $(\bowtie)$

Department of Biology, Technical University of

Darmstadt, 64287 Darmstadt, Germany

e-mail: luettge@bio.tu-darmstadt.de emergence helps to advance on the rocky paths towards understanding the complexity of life.

Keywords Biosphere - Complexity - Epigenetics · Evolution · Gaia · Genome · Holism · Holobiont . Information · Network hierarchy · Reductionism . Self-organization $\cdot$ Systems biology $\cdot$ Whole-plant physiology

\section{Introduction}

Living organisms are made up of different parts, which are building-blocks or modules. Particularly the plants are often considered to be modular organisms. Their parts are thought to be semi-independent or even totally independent (Haukioja 1991). In this vein the performance of whole plants is seen as a by-product of responses of modules (de Kroon et al. 2005). This leads to the provocative view that "a tree is not a tightly integrated organism but a by-product of its parts" (Haukioja 1991). Philosophically this is pronounced materialism. It elicits the complaint that with each successful step towards understanding mechanisms biology diverts more and more from understanding life, which is a fundamental intrinsic contradiction within biology and its tragedy as a science (von Weizsäcker 1954). 
A counterbalance is given when biology unravels self-organization of modules with integration into unitary wholeness. This is emergence, where new systems appear which have completely new properties as compared to the basic modules. Behind this is the concept of "fulguration" of Konrad Lorenz (1977) as a dramatic event of appearance of something new coming up like a flash of lightning. Interactions of modules and their integration in clusters of modules lead to systems with completely new innate qualities which cannot be predicted by even the closest examination of the modules per se and in isolation. As already noted by Aristotle (384-322 BC) the whole is more than the sum of its parts.

\section{Instability, change and self-organization for emergence}

Instability allows changes with fulguration, where the pathway from modules to emergence of systems with completely new properties on a next higher scalar level is self-organization. In a recent assay Schmidt (2019) relates these four terms. Living organisms are all open systems thermodynamically only metastable in pseudo-steady states (Netter 1959). Instabilities are a necessary condition for changes, where new complex systems can emerge and where self-organization is the driving force.

This driving force is intrinsically inherent in the systems themselves - as the term "self" says-and does not come from the outside environment. Selforganization is contrasting any other extrinsically controlled forms of organization (zu Castell et al. 2019). The concept of self-organization originated in the early 1960s, although Immanuel Kant (1724-1804) had already spoken of "self-organizing beings" (Schmidt 2019). The modern theories of selforganization are spanning a number of disciplines and represent rich and broad thinking (Auffray et al. 2003; Schmidt 2019), incorporating aspects, such as "complex systems theory, nonlinear dynamics, chaos theory, synergetics, dissipative structures, fractal geometry, and autopoiesis theory" (Schmidt 2019), or in other words, self-sustainment, homeostasis, metabolism, differentiation and growth (Fuchs 2020). These theories address emergence of novel patterns being more complex systems than the merging modules integrating each other in selforganization. Life is self-organization and emergence.

Thus, fulguration and emergence are also meaning new pattern formation. Patterns resulting from internal self-organization emerge on a hierarchy of scalar levels like multi-level networks (Matyssek and Lüttge 2013, zu Castell et al. 2019; below: Sect. 4).

\section{Modularity and emergence}

The pathway from modules to the emergence of systems with new properties on a next higher level of scaling is self-organization (Schmidt 2019). The modules of trees are obviously stems and branches, leaves and roots. On the molecular level modules of more complex emerging systems are individual proteins. The proteome is the sum of all these modules. Quantification of protein interactions for emergence is approached mathematically (Wegner 2019; Wegner and Hao 2020). Self-organization of selections of these protein modules leads to emergence of complex multi-subunit enzyme systems, e.g. the ATPases synthesizing ATP in mitochondria and chloroplasts or transporting protons across tonoplasts, the photosynthetic enzyme ribulose-bisphosphate carboxylaseoxygenase or the multi-enzyme-complex of pyruvatedecarboxylase with the subunits pyruvate-dehydrogenase, dihydrolipoyl-transacetylase and dihydrolipoyldehydrogenase, to name just a few from a plethora of examples in metabolism.

This suggests that we have modularity and emergence on all possible levels of scaling. Atomic particles are modules of atoms, which in turn are modules of molecules. Molecules form membranes which build up compartments and organelles, i.e., the modules of cells. Cells create tissues, which constitute organs, such as the named modules of trees exemplifying entire plants, which become the elements of ecosystems, which then are the building-blocks of biomes, from which eventually the entire biosphere or Gaia sensu Lovelock $(1979,2009)$ is emerging as the ultimate integrated unit of life on Earth (Matyssek and Lüttge 2013). This hierarchy of complex emerging systems covers many orders of magnitude in space and time. Interestingly in the double logarithmic plot of Fig. 1 they follow approximately a straight line.

At each scalar level the building-blocks or modules from which the more complex systems are emerging 
Fig. 1 Range of emerging systems of life in space and time. (Colors correspond to a schematic system of network-hierarchy plotted in Fig. 2). (Color figure online)

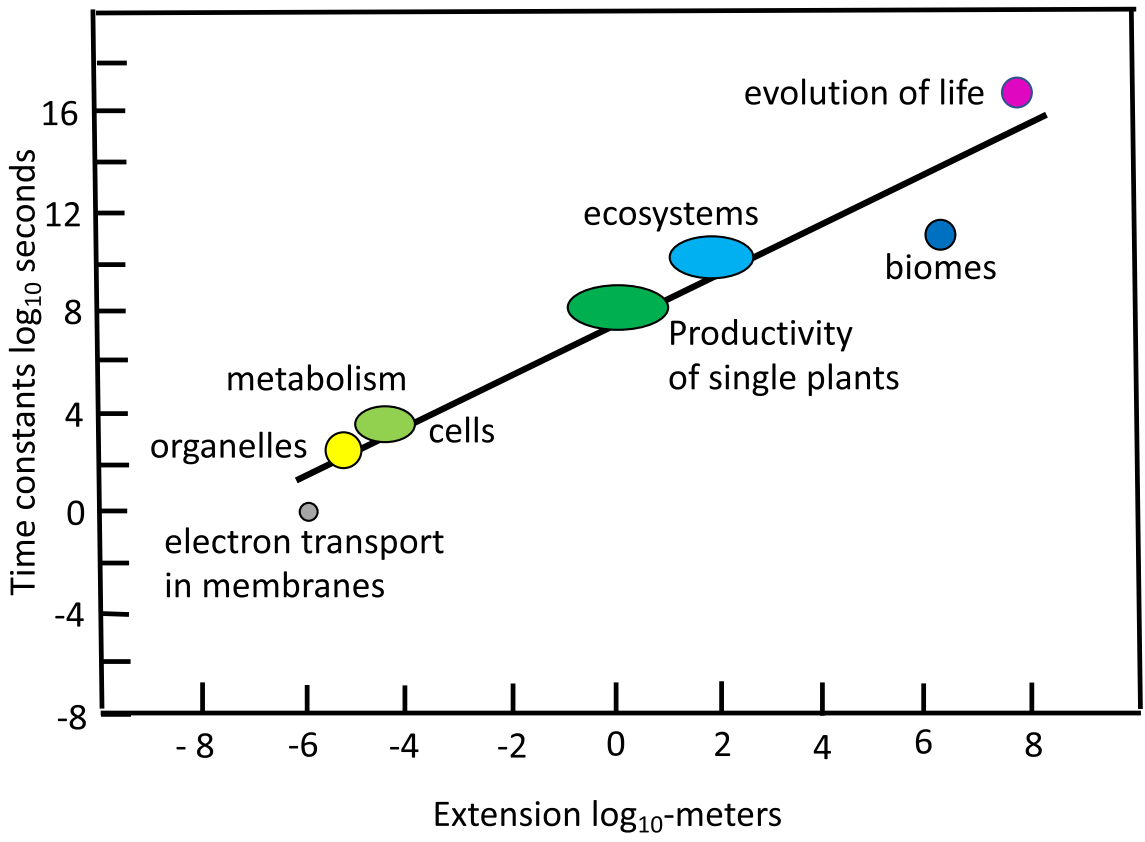

are themselves complex. We have a hierarchy of modules which we can consider as a hierarchy of networks (Lüttge 2019), as symbolized by the cartoons of Fig. 2. At the bottom of the hierarchy drawn the yellow modules form the yellow network. If we take this entire network as a new module, i.e., envisage it being condensed to a new more complex light-green building-block, this can form the new light-green network. Continuation of this principle leads to building up the extended hierarchy of modules and systems emerging from them, i.e., dark-green, lightblue, dark-blue and magenta in the scheme of Fig. 2 and more concretely in Fig. 1.

Similarly, we observe a hierarchy in the laws of physics. According to Laughlin $(2005,2010)$ all laws of physics are emergent. The laws governing an integrated system are independent of the laws pertaining to the individual processes underneath. The laws of thermodynamics and of classical mechanics emerge from the laws of quantum mechanics. The levels of macroscopic physics of matter are governed by intermediate macroscopic laws. An example from thermodynamics for an emergent law is the general gas equation

$\mathrm{P} \times \mathrm{V}=\mathrm{R} \times \mathrm{T}$,

which describes a gas by its pressure, $\mathrm{P}$, and temperature, $\mathrm{T}(\mathrm{V}$ is volume and $\mathrm{R}$ is the general gas constant). However, the individual molecules constituting the gas do not have pressure or temperature. Pressure and temperature are emergent statistical properties of a large number of gas molecules. Another example familiar to plant physiologists is the osmotic law explaining the development of hydrostatic pressure, e.g., turgor pressure, where the solute molecules generating osmotic gradients do not have a pressure.

These considerations lead us to an overview of modularity and emergence (Fig. 3). Self-organization and emergence create unique unitary systems. This is holism with integration of components and unfolding complexity. Separation of the parts isolates repetitive modules. This is reductionism with specialization on the components. The genome comprises the information for the individual modules. Epigenetics determine how this information is read and realized for building integrated unitary systems which pave the way closer to understanding life.

\section{Unitary integrated systems: the holobiont concept}

The original definition of the holobiont is: A host organism in interaction with all associated microorganisms as a unit for selection in evolution. Very typical holobionts are humans. Each of us is carrying 


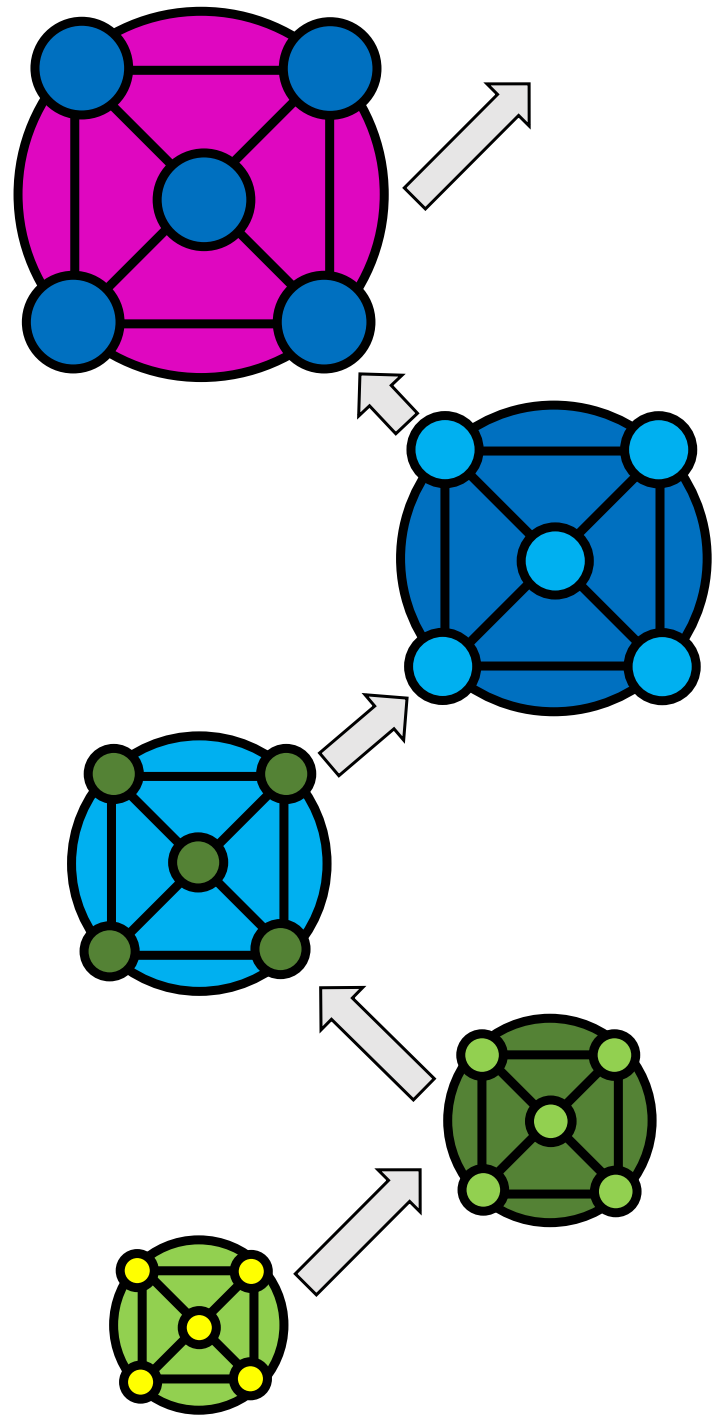

Fig. 2 Hierarchy of networks with knots or modules (circles) and edges (lines) on increasing scaling levels. From bottom to top: The yellow knots or modules are condensed to light green modules forming a new light green network on a higher scalar level. This light green network is condensed to dark green modules forming a new dark green network on the next higher scalar level. This is condensed to the light blue modules forming the light blue network followed by condensation to the dark blue modules forming the dark blue network condensed to the magenta modules etc. (Color figure online)

about $1 \mathrm{~kg}$ of bacteria with us, i.e., 10-100 bacterial cells per body cell. With them we have a hologenome, where these bacteria contribute 100-150 fold the number of genes than our own genome (zu Castell et al. 2019). Because without these symbionts we could not survive, we have here an example of

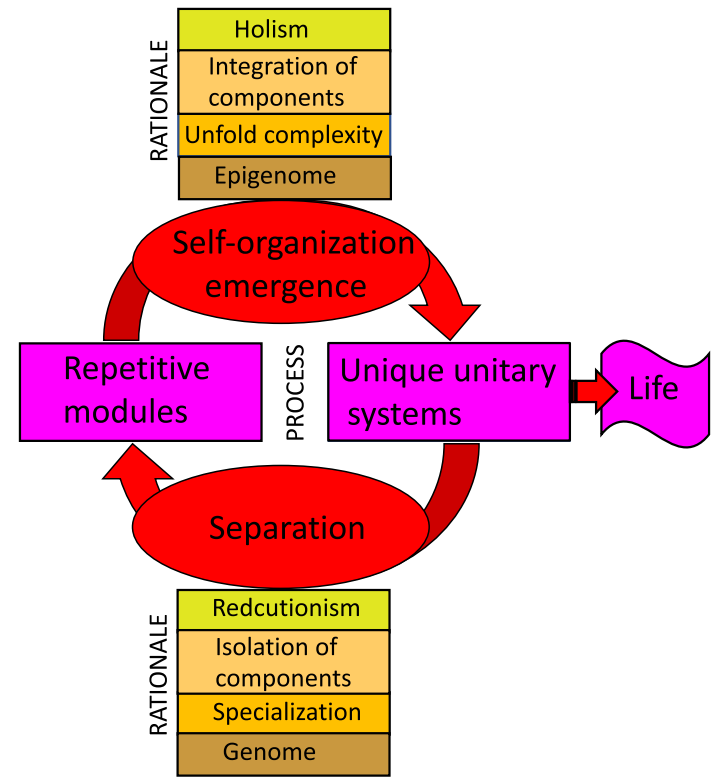

Fig. 3 Processes of self-organization and separation of modules and emerging unitary systems and their rationale

emergence. Holobionts are emergent. Could we, therefore, not consider all the emergent systems of Fig. 1 as holobionts? When we replace "host organism" by "central organism" and "microorganisms" by "organisms" in general, we arrive at the broader definition of holobionts as: A central organism in interaction with all associated organisms as a unit for selection in evolution (Matyssek and Lüttge 2013; Lüttge and Scarano 2019). This then applies to higher spatio-temporal structures as depicted in Fig. 1.

Matyssek and Lüttge (2013) list and describe a number of holobiont-systems at increasing levels of scaling, such as virus-infected unicellular organisms, symbioses between unicellular organisms, lichens, biofilms, soil crusts, mycorrhized forests, ecosystems, biomes and the biosphere. The endosymbiosis theory of the evolution of eukaryotic cells tells us that the organelles mitochondria and in plants in addition the chloroplasts arose from prokaryotic endo-symbionts. This implies that all eukaryotic organisms carry the holobiont syndrome (Matyssek and Lüttge 2013). Forests emerge from integration of the modules of individual trees and have fundamentally different properties than trees in isolation. Forests are holobionts as their trees are connected by the hyphae of mycorrhiza. Perhaps at these higher levels of scaling we may better speak of "holobiont-like systems" 
(HLS). A central key word in the definitions of holobionts is "interaction". The living organisms are modules from which ecosystems emerge, and they interact, so that ecosystems are also HLSs. Similarly, biomes with the modules of ecosystems are HLSs. Biomes are the modules of the biosphere, and the entire biosphere or Gaia is the ultimate case of an HLS (Matyssek and Lüttge 2013; zu Castell et al. 2019).

Since holobionts by definition are units for selection in evolution, the intriguing question arises if HLSs and eventually Gaia at the highest level of scaling are subject to evolution as addressed by Castell et al. (2019). Stephen Jay Gould (2002) has widened the concept of the unit in Darwinian selection. He is not only considering the organism as the unit of selection but particularly also the species. In a broader view, according to him, genes, cell lineages, organisms, demes, species and clades, can be subjected to Darwinian selection. However, forcefully and with colorful language he rejects evolution of what he calls "large items in nature", and where Gaia is the most prominent example. They are not evolutionary individuals and not units of selection, where the key elements are competitive skill and heredity. The HLSs at the higher scalar levels and Gaia have no competitors and no children. Reluctantly Gould admits that communities maintain some functional coherence and boundaries to be defended, as well as some potential of splitting off "daughter communities". However, he has fundamental reservations accepting these ecological units to be Darwinian agencies.

Considering competition, we note that this is not only a fight between individual emergent units but also of modules within the units. Roux (1881) is viewing the fight of parts over resource allocation within organisms as a fight for survival. This would similarly be the fight of the parts or organisms in ecosystems or the parts in higher level HLSs. With this view of systems-internal competition one of the important aspects of evolution is realized in the HLSs. Moreover, selection is not only based on competition but also resulting from choices individuals have taken. Furthermore, we should not maintain selection as a nondisputable conviction and dogma (Kimura 1983; Scherer 2017). Currently, in the twenty-first century, it is argued that we need to move on from the so socalled great synthesis of the 1930s to 1940s and advance the theory of evolution in an "extended synthesis" (Scherer 2017).
Holobionts as listed above, e.g., symbiotic units like lichens or humans, evidently undergo evolution, so why not also the examples of holobionts at the community level, the HLSs ecosystems and biomes? The biosphere-geosphere-atmosphere interactions driven by the expression of life accumulate to Gaian interactions at the global scale. Gaia, as we currently know it, evolved from earlier versions but none of the precursors survived. We do not need to accept these precursors following each other to be "parents" and "children" for understanding that there was a passing on of physical characteristics, i.e., some kind of heredity. There was a sequential selection for stabilization rather than for specific traits or particular genotypes. The self-stabilizing feedback of bioticabiotic interactions are in line with evolution and natural selection because they constantly force Gaia to adapt.

\section{Systems biology in the 1970s and 1980s}

Historically it is remarkable that already 50 years ago whole-plant physiology had been developed (Lüttge 2013). It recognized plants as highly integrated complex systems functioning by coordination of their parts. This was systems biology. It happened more than a decade after that progress, when in the 1990s and early 2000s some authors returned to an extreme modularity, which considered plants as mere byproducts of their parts (see above Sect. 1). By contrast, currently systems biology is much advanced again as a most "modern" conception with studying signaling, transfer of information and integration of parts and with attempts to model and to construct complex biological units for a better understanding of the functions of life and for biotechnological applications.

Plants are sedentary organisms living simultaneously in two contrasting environments, i.e., in the mineral pedosphere with their roots and in the gaseous atmosphere with their shoots. The whole-plant physiology in the 1970s therefore was dedicated to rootshoot interactions and unfolded plant-systems biology from that. Among the three major modules of vascular plants (1) the leaves perform photosynthesis, generate metabolites for growth, by transpiration are involved in water relations, and determine the energy status; (2) the roots acquire water and minerals, and (3) the shoots serve integration by distribution of materials 


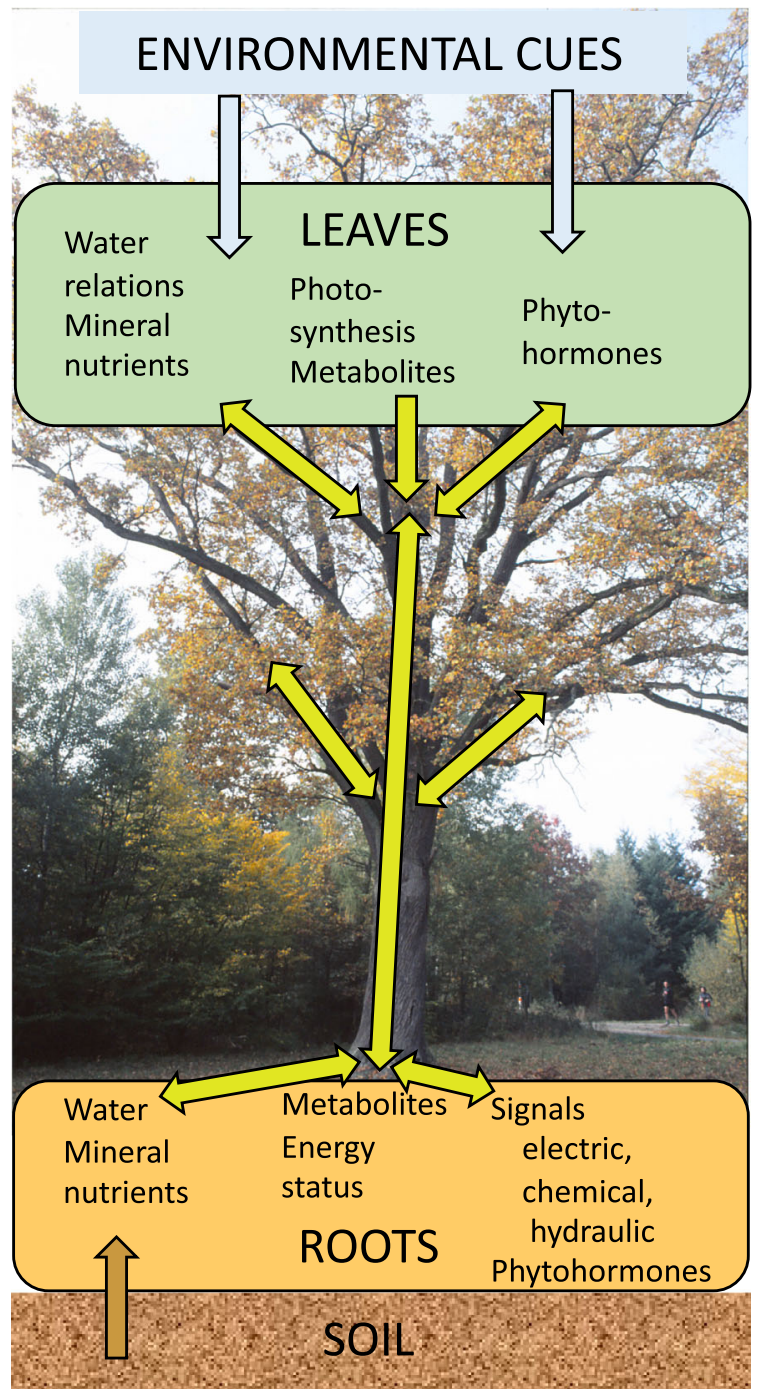

Fig. 4 The whole plant as a system

(mineral nutrients and metabolites) and by signaling (Fig. 4).

Outstanding advocates of a whole-plant perspective of integration were Pitman (1975) and Sutcliffe (1976a, b). Moreover, Jeschke and Pate in a remarkable series of publications have documented wholeplant phloem-xylem cycling of a variety of compounds (Jeschke et al. 1985, 1987; Wolf and Jeschke 1987; more details and references in Lüttge 2013). A focus of many of these studies was in the field of plant mineral nutrition, i.e., the uptake, transport and wholeplant distribution of mineral nutrients (Lüttge 2013). Sutcliffe (1976a, b) used a germinating-seeds model to study the mobilization and whole-plant partitioning of stored resources of $\mathrm{C}$ and $\mathrm{N}$ compounds and minerals, with the conclusion that "a vascular plant functions as an integral unit". Nitrogen and sulfur are required by the plants in the reduced forms of $-\mathrm{NH}_{2}$ and $\mathrm{S}^{2-}$, respectively, but are available in the soil in the oxidized forms of $\mathrm{NO}_{3}{ }^{-}$and $\mathrm{SO}_{4}{ }^{2-}$. The capacity of roots, however, is not sufficient for their reduction. Reduction equivalents produced by photosynthetic electron transport in the leaves provide the required reduction power. Root and shoot interact in the whole plant for $\mathrm{N}$ - and S-assimilation. Only when $\mathrm{NO}_{3}{ }^{-}$ levels in the roots are low, reduction can occur in the roots (Kirkby and Knight 1977). More $\mathrm{NO}_{3}{ }^{-}$taken up by the roots is transported to the shoots, where $\mathrm{NO}_{3}{ }^{-}$ reduction to $\mathrm{NH}_{4}^{+}$via nitrate and nitrite reductases generate stoichiometric amounts of $\mathrm{OH}^{-}$ions. Alkalization of the cytoplasm of leaf cells is prevented by the synthesis of malic acid, which neutralizes the $\mathrm{OH}^{-}$, and the remaining malate ${ }^{2-}$ anions are transported to the roots, where malate can serve as a substrate for metabolism and energization (BenZioni et al. 1971). In a similar way inter-organ S-nutrition is regulated (Herschbach and Rennenberg 1994).

\section{Systemic and ecological signaling}

Systemic signaling between the parts within whole plants is essential for the regulation of all aspects of plant life, i.e., growth, development, metabolism, acquisition of resources, interactions with the environment. A classic example of the role of signaling in whole-plant performance is water-relations of the roots and the shoots with their leaves (Davies and Zhang 1991; Gil et al. 2008). When roots sense water stress due to low soil-water potential, they can warn the leaves before these themselves sense the problem. Plants experimentally can be grown with a split rootsystem where parts of the roots are in a chamber with soil of high and low water potential, respectively. In such experiments the leaves obtain a signal of waterstress from the low water potential chamber and close their stomata, although there is no water-stress at all, because enough water is supplied by the roots in the chamber of high water potential.

Signaling in whole-plant performance has been reviewed in some detail by Lüttge (2013), and this is summarized here in Table 1. There are three major types of signals, namely electric, chemical and 
Table 1 Signaling in whole plants (*VOCs: volatile organic compounds; ** in one case $40000 \mathrm{~mm} \mathrm{~s}^{-1}$ was reported)

\begin{tabular}{|c|c|c|c|}
\hline Types of signals & Subtypes of signals & Propagation & Pathways of propagation \\
\hline \multirow[t]{3}{*}{ Electric } & Action potentials & Fast $1-50 \mathrm{~mm} \mathrm{~s}^{-1 * *}$ & Phloem \\
\hline & Variation potentials & $0.5 \mathrm{~mm} \mathrm{~s}^{-1}$ & Cell to cell \\
\hline & System potentials & $1-3 \mathrm{~mm} \mathrm{~s}^{-1}$ & Cell to cell \\
\hline \multirow[t]{3}{*}{ Chemical } & Metabolites & Slow $0.15-0.30 \mathrm{~mm} \mathrm{~s}^{-1}$ & Phloem (xylem) \\
\hline & Phytohormones & Slow & Xylem, phloem, cell to cell \\
\hline & Pheromones, VOCs* & Fast & Atmosphere \\
\hline \multirow[t]{5}{*}{ Hydraulic } & Water potential gradients & Slow & Cell to cell \\
\hline & Turgor pressure & Slow & Cell to cell \\
\hline & Osmotic pressure & Slow & Cell to cell \\
\hline & Shock waves & Fast & Xylem \\
\hline & Moving water columns & Slow & Xylem \\
\hline
\end{tabular}

hydraulic signals. During their propagation they can be translated into each other, as it is also the case in the example given above, where the roots send hydraulic signals, which are translated into the chemical signal of the phytohormone abscisic acid (ABA) and into electric signals.

Some signals are rapidly propagated and others more slowly. The fastest ones are the electric action potentials. They move electrotonically along the membranes of sieve tubes in the phloem with $1-50 \mathrm{~mm} \mathrm{~s}^{-1}$, i.e., much faster than the solute transport with $0.15-0.30 \mathrm{~mm} \mathrm{~s}^{-1}$. Other types of electric signals are propagated more slowly.

Among the chemical signals the distribution of metabolites via the pathways of long-distance transport, particularly the phloem but also the xylem, is carrying information about their production and availability. This, however, is rather coarse signaling especially controlling long distance source-sink relations. A large group of chemical signals involved in fine tuning is that of the phytohormones, where the stress hormone ABA mentioned above is just one prominent example. They are propagated rather slowly from cell to cell, but all classic phytohormones are also mobile in both long-distance transport pathways, i.e., the xylem and the phloem (Heil and Ton 2008).

Volatile signaling substances are propagated via the gas phase much more rapidly. They are called pheromones, such as the phytohormone ethylene, and there are other effective volatile organic compounds (VOCs). The VOCs are also involved in ecological signaling. Herbivore and pathogen defense reactions comprise whole-plant hormonal regulation (Kessler and Baldwin 2002). When plants are attacked by herbivores, they generate VOCs, which warn other parts of the same plant via the gas phase much more rapidly than by phytohormone transport within the plant (Heil 2010) to activate production of repellants and other defense mechanisms. Such VOCs also warn other plant individuals including those of different species in the habitat (Baluška and Ninkovic 2010; Ninkovic 2010).

Hydraulic signals, such as water potential, osmotic potential and turgor pressure (Matyssek et al. 1991; Tang and Boyer 2003; Grams et al. 2007), are propagated slowly from cell to cell. The movement of water columns in the xylem (Cermak et al. 1993) is also slow compared to very fast shockwaves produced in the xylem (Matyssek et al. 1991).

\section{Emergence and memory}

All living organisms that have bio-membranes, polynucleotides and proteins can develop memory. Can memory affect or even determine what emerges from integration of modules?

We can detect memory at the level of molecular genetics. Memory is inherent in the regulator-operator theory of operon function in gene regulation by Jacob and Monod (Nobel prize 1965) based on studies with the prokaryote bacterium Escherichia coli (Fig. 5). Regulator genes can produce either active or inactive repressor molecules. An active repressor can bind to an operator gene and then the structure genes regulated 


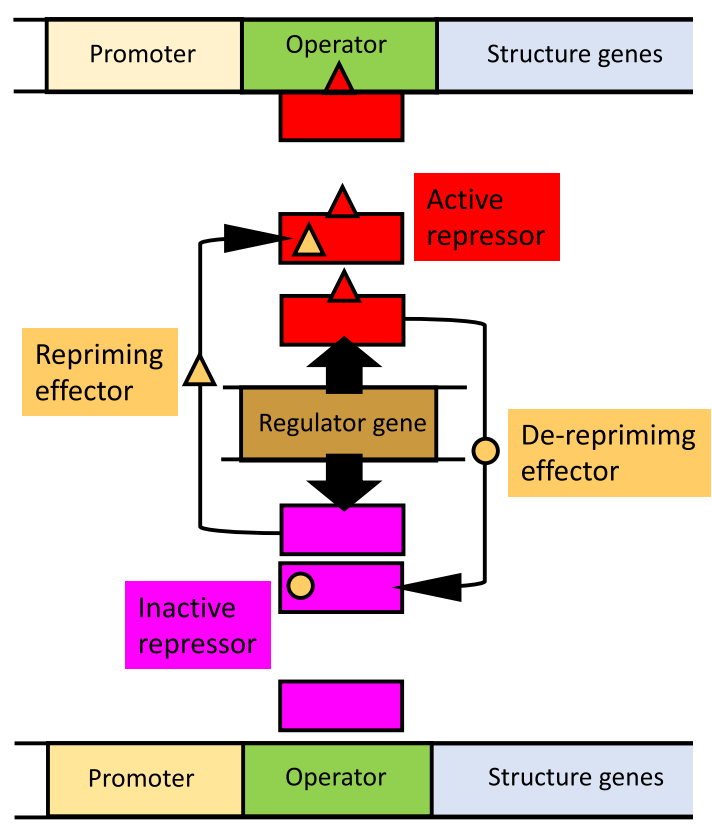

Fig. 5 Regulator-operator theory of operon function after Jacob and Monod

by the operator in the operon are reprimed or locked. When the repressor is inactive these genes are unlocked. External cues can activate or inactivate repressors, e.g., small molecules binding to them. In $E$. coli the addition of $\beta$-galactoside to the culture medium induces for its metabolism the synthesis of $\beta$ galactosidase, which is not normally expressed. When one removes the substrate after the induction and thereafter adds it again after a certain time, one notes that the cells have retained, i.e., remembered, their capacity for $\beta$-galactoside uptake and metabolism. The length of the time the cells may remember it depends on repressor-turnover. Similarly, the cells of the eukaryotic unicellular alga Chlorella vulgaris retain memory of the induction of glucose uptake for a little more than $10 \mathrm{~h}$ in the absence of glucose (Tanner et al. 1970).

In Higher Plants we distinguish memories with capacities of

- Habituation, learning or priming,

- Store (STO) and recall (RCL) functions, and

- Epigenetic modifications

(Thellier

et

al.

1982, 2011, 2015, 2017a, b, 2004, 2013; Thellier and Lüttge 2013; Hütt et al. 2015; Lüttge and Thellier 2016).

The habituation, learning or priming memory provides rather direct responses to stimuli and environmental cues. These change the way the plant transduces one or several subsequent stimuli. Repeated harmless stimuli are remembered and ignored ("familiarization"). Increasingly violent responses are generated in response to harmful stimuli ("sensitization").

The STO/RCL-memory is more complex with the involvement of STO and RCL genes. External stimuli and environmental cues elicit various signals which release effectors and may also involve the biological clock in some cases (Hütt et al. 2015; Lüttge and Thellier 2016). These effectors unlock and activate STO and RCL genes, the products of which cause the emergence of processes of life (Fig. 6). Both the two functions of STO and RCL always need to be active for emergence. However, they are independent functions and can be activated in different sequences during time. In Fig. 7 the various possibilities are depicted. The first four are the controls in experiments. Without input (1) or with only a stimulus and storge (2), and respectively, only an activation of the RCL function (3), there is no emergence. If STO and RCL functions are activated simultaneously there is immediate emergence (4), which does not show memory, of course. If STO and RCL activation occur separated in time, emergence following the second event proves memory, independent of which one occurs first, STO before RCL (5), or RCL before STO (6). RCL can even be activated/inactivated repeatedly (7). MarieOdile Desbiez and Michel Thellier in their extensive studies of plant memory (refs. above) have shown examples for all of these cases, which are listed in Table 2. The memorized stimuli (STO) can be of many kinds, e.g., mechanical (touching, pricking with a fine needle, wounding), drought, cooling, cold shock, manipulation, chemical (droplets with different chemicals) etc.

Seedlings have opposite axillary buds at their cotyledons which only break out when apical dominance is relieved by decapitation. There is full symmetry, i.e., one cannot predict which of the two buds breaks out first and takes over the lead. However, if one pricks one of the cotyledons with a needle (STO) it is the bud of the opposite cotyledon which preferentially breaks out after decapitation (RCL). The RCL 
Fig. 6 Verbatim scheme of the networks of memory functions. In the blue and red boxes from left to right: Store (STO)/Recall (RCL), Habituation/Priming and Epigenetic memory. (Color figure online)

Fig. 7 Sequences of stimulus and store (STO) and recall (RCL) functions affecting the emergence (magenta) of structures from memory
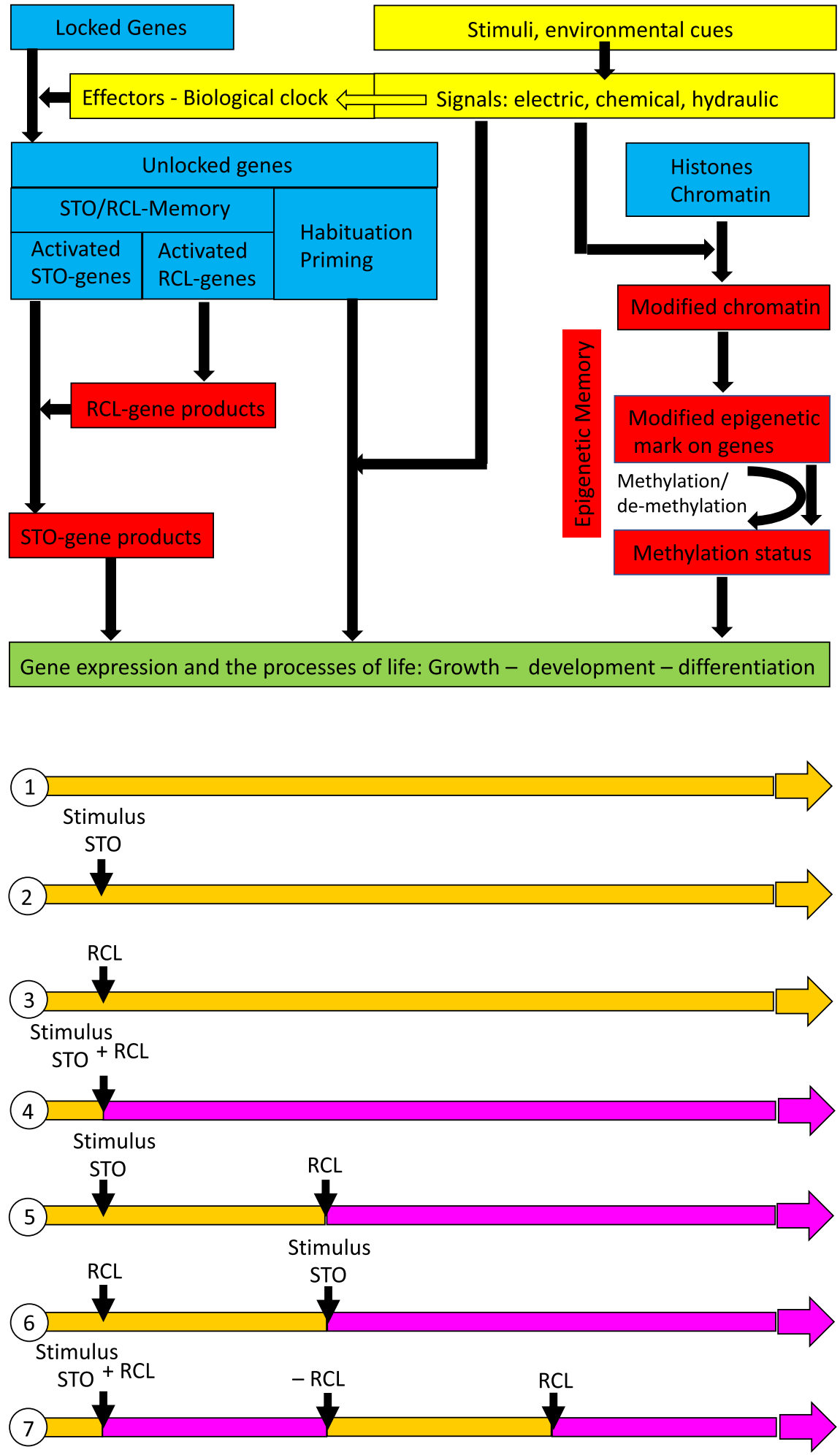
Table 2 Examples of memory in higher plants from the work of Marie-Odile Desbiez and Michel Thellier (Thellier 2015, 2017a, b)

\begin{tabular}{|c|c|c|c|c|}
\hline Object & $\begin{array}{l}\text { Emerging structure } \\
\text { or function }\end{array}$ & $\begin{array}{l}\text { Stimulus } \\
\text { STO-function }\end{array}$ & RCL-Function & No. in Fig. 6 \\
\hline \multirow[t]{4}{*}{ Bidens pilosa L. } & Breaking symmetry & Pricking & Decapitation & \\
\hline & of cotyledonary & Cotyledon & & \\
\hline & bud out-break & First & Second & 5 \\
\hline & & Second & First & 6 \\
\hline \multirow[t]{2}{*}{ Bidens pilosa $\mathrm{L}$. } & $\begin{array}{l}\text { Inhibition of } \\
\text { hypocotyl } \\
\text { elongation }\end{array}$ & Pricking & $\begin{array}{l}\text { Transfer from } \\
\text { nutrient } \\
\text { solution to pure } \\
\text { water }\end{array}$ & \\
\hline & & First & Second & 5 \\
\hline \multirow[t]{4}{*}{ Linum usitatissimum L. } & $\begin{array}{l}\text { Formation of } \\
\text { epidermal } \\
\text { meristem }\end{array}$ & $\begin{array}{l}\text { Manipulation by } \\
\text { transfer to } \\
\text { fresh medium }\end{array}$ & $\begin{array}{l}\text { Removal of } \mathrm{Ca}^{2+} \\
\text { from } \\
\text { the medium }\end{array}$ & \\
\hline & & First & Second & 5 \\
\hline & & Second & First & 6 \\
\hline & & & Repeated & 7 \\
\hline
\end{tabular}

First, second, repeated refers to the sequence in which STO and RCL functions were activated as shown in Fig. 6

may occur up to 2 weeks later than STO proving memory. After a short stimulus-response period (2 days) symmetry breaking only occurs when decapitation is in the morning and not when it is at midday. This suggests involvement of the biological clock. Hypocotyl elongation is affected by pricking (STO). It is inhibited upon transfer from nutrient solution to water (RCL). Formation of an epidermal meristem is elicited after manipulation of the plants by transferring them to a fresh medium (STO) with RCL by removing calcium from the medium.

Epigenetic modifications of the genome are brought about by acetylation/methylation of histones and the cytosine residues of DNA. Methylation hinders access of transcription factors, closes the chromatin and therefore locks genes. With acetylation the chromatin is open. Changes of methylation/de-methylation occur in response to environmental cues and can be memorized and even be inherited to subsequent generations (Jablonka and Lamb 1989; Bird 2002; Kakutani 2002; Molinier et al. 2006; Bond and Finnegan 2007; Boyko and Kovalschuk 2008; Chinnosami and Zhu 2009; Saze 2008; Chen et al. 2010; Kinoshita and Seki 2014; Adams 2010; more references and details in Thellier and Lüttge 2013). This is the epigenetic stress memory (Thellier and Lüttge 2013) (Fig. 6).

Epigenetic modifications have no effect whatsoever on the sequence of nucleotide units in the DNA, but they regulate reading of the genetic information. This effects emergence. An example is symmetry of flowers in Linaria vulgaris (Mill.). Normally its flowers have bilateral symmetry. However, if only one single promoter region is methylated, i.e., the promoter of the gene CYCLOIDEA, the flowers show a radial symmetry and are so different that Charles Linné even created a different genus Peloria. With the appeal of symmetry (Lüttge and Souza 2019) this reveals an esthetic implication of emergence. My favorite metaphor is the grand piano. It is there with all its modules, keys, strings, pedals, wooden body. But there is no music. It depends who is playing it. If played by an ingenious pianist the most divine music will emerge. It is similar to how the genome is played. A little nematode and the fruit fly have 15-20,000 genes, the weed Arabidopsis thaliana (L. (Heynh.)) has 27,000 genes and humans have 25,000 genes, only about $300(1.3 \%)$ different from the Chimpanzee. These organisms with so similar genome sizes are of vastly different complexity. Another example of the poesy inherent in emergence we owe to Robert Laughlin $(2005,2010)$. Apparently erratic individual patches of paint thrown at a canvas are modules of impressionist paintings. A beautiful garden can emerge, such as the Jardin de Giverny by Claude Monet. 


\section{Emergence and integration: understanding complexity of life}

Moving ahead from modularity to emergence in plants over a broad hierarchy of scalar levels of integration, we came across stimuli and signals and the information inherent in them. We noted the storage of information in memory. We were enthralled by selforganization as a feature of holism. With the enthusiasm promoted by the creative fulguration of selforganization of modules into the emergence of exciting new systems, biology diverts from the reductionism and materialism of bare modularity. Built into the understanding of emergent systems unraveling of mechanisms does not divert biology from understanding life (see von Weizsäcker, Sect. 1), but helps to advance on the rocky paths towards understanding the complexity of life. With understanding emergence, biology will understand life without leaving strict rules of natural science, and without losing sight of the different spiritual qualities of life. A rose is both, a complex, integrated, emergent plant biological system and a flower of overwhelming beauty.

Acknowledgements This review article is a written version of a video-presentation at SES 2020 (Simpósio de Ecofisiologia Sistêmica) conference in Brazil held on 4th November 2020. I thank Gustavo Maia Souza for his great support and invitation to present the video-lecture and to write the article.

Funding Open Access funding enabled and organized by Projekt DEAL. There was no funding of this review article.

\section{Compliance with ethical standards}

Conflict of interest There are no conflicts of interest. The author wrote the review article alone.

Open Access This article is licensed under a Creative Commons Attribution 4.0 International License, which permits use, sharing, adaptation, distribution and reproduction in any medium or format, as long as you give appropriate credit to the original author(s) and the source, provide a link to the Creative Commons licence, and indicate if changes were made. The images or other third party material in this article are included in the article's Creative Commons licence, unless indicated otherwise in a credit line to the material. If material is not included in the article's Creative Commons licence and your intended use is not permitted by statutory regulation or exceeds the permitted use, you will need to obtain permission directly from the copyright holder. To view a copy of this licence, visit http://creativecommons.org/licenses/by/4.0/.

\section{References}

Adams KL (2010) Dandelions 'remember' stress: heritable stress-induced methylation patterns. New Phytol $185: 867-868$

Auffray C, Imbeaud S, Roux-Roquié M, Hood L (2003) Selforganized living systems: conjunction of a stable organization with chaotic fluctuations in biological space-time. Phil Trans R Soc Lond A 361:1125-1139

Baluška F, Ninkovic V (2010) Plant communication from an ecological perspective. Springer, Berlin

BenZioni A, Vaadia Y, Lips SH (1971) Nitrate uptake by roots as regulated by nitrate reduction products of the shoot. Physiol Plant 24:288-290

Bird A (2002) DNA methylation patterns and epigenetic memory. Genes Dev 16:6-21

Bond DM, Finnegan EJ (2007) Passing the message on: inheritance of epigenetic traits. Trends Plant Sci 12:211-216

Boyko A, Kovalchuk I (2008) Epigenetic control of plant stress response. Environ Mol Mutagen 49:61-72

Cermak J, Matyssek R, Kucera J (1993) Rapid response of large, drought-stressed beech trees to irrigation. Tree Physiol 12:281-290

Chen M, Lv S, Meng Y (2010) Epigenetic performers in plants. Dev Growth Differ 52:555-566

Chinnusami V, Zhu J-K (2009) Epigenetic regulation of stress responses in plants. Curr Opin Plant Biol 12:133-139

Davies WJ, Zhang J (1991) Root signals and the regulation of growth and development of plants in drying soil. Annu Rev Plant Biol Plant Mol Biol 42:55-76

de Kroon H, Huber H, Stuefer JF, van Groenendael JM (2005) A modular concept of phenotypic plasticity in plants. New Phytol 166:73-82

Fuchs T (2020) Verteidigung des Menschen. Grundfragen einer verkörperten Anthropologie. Suhrkamp, Berlin

Gil PM, Gurovich L, Schaffer B, Alcayaga J, Rey S, Iturriaga R (2008) Root to leaf electrical signaling in avocado in response to light and soil water content. J Plant Phys 165:1070-1078

Gould JG (2002) The structure of evolutionary theory. Harvard University Press, Cambridge, MA

Grams TEE, Koziolek C, Lautner S, Matyssek R, Fromm J (2007) Distinct roles of electric and hydraulic signals on the reaction of leaf gas exchange upon re-irrigation in Zea mays L. Plant Cell Environ 30:79-84

Haukioja E (1991) The influence of grazing on the evolution, morphology and physiology of plants as modular organisms. Philos Trans R Soc Lond Ser B 333:241-247

Heil M (2010) Within-plant signalling by volatiles triggers systemic defences. In: Baluška F, Ninkovic V (eds) Plant communication from an ecological perspective. Springer, Berlin, pp 99-112

Heil M, Ton J (2008) Long distance signalling and plant defence. Trend Plant Sci 13:264-272

Herschbach C, Rennenberg H (1994) Influence of glutathione (GSH) on net uptake of sulphate and sulphate transport in tobacco plants. J Exp Bot 45:1069-1076

Hütt MT, Lüttge U, Thellier M (2015) Noise induced phenomena and complex rhythms: a test scenario for plant systems biology. In: Mancuso S, Shabala S (eds) Rhythms 
in plants: dynamic responses in a dynamic environment, 2nd edn. Springer, Cham, pp 279-321

Jablonka E, Lamb MJ (1989) The inheritance of acquired epigenetic variation. J Theor Biol 139:69-83

Jeschke WD, Atkins CA, Pate JS (1985) Ion circulation via phloem and xylem between root and shoot of nodulated white lupin. J Plant Physiol 117:319-330

Jeschke WD, Pate JS, Atkins CA (1987) Partitioning of $\mathrm{K}^{+}$, $\mathrm{Na}^{+}, \mathrm{Mg}^{++}$, and $\mathrm{Ca}^{++}$through xylem and phloem to component organs of white lupin under mild salinity. J Plant Physiol 128:77-93

Kakutani T (2002) Epi-alleles in plants: inheritance of epigenetic information over generations. Plant Cell Physiol 43:1106-1111

Kessler A, Baldwin IT (2002) Plant responses to insect herbivory: the emerging molecular analysis. Annu Rev Plant Biol 53:299-328

Kimura M (1983) The neutral theory of molecular evolution. Cambridge University Press, Cambridge

Kinoshita T, Seki M (2014) Epigenetic memory for stress response and adaptation in plants. Plant Cell Physiol 55:1859-1863

Kirkby EA, Knight AH (1977) Influence of the level of nitrate nutrition on ion uptake and assimilation, organic acid accumulation, and cation-anion balance in whole tomato plants. Plant Physiol 60:349-353

Laughlin RB (2005) A different universe-reinventing physics from the bottom down. Basic Books, New York

Laughlin RB (2010) Abschied von der Weltformel. Die Neuerfindung der Physik, 2nd edn. Piper, München

Lorenz K (1977) Die Rückseite des Spiegels. Versuch einer Naturgeschichte menschlichen Erkennens. Deutscher Taschenbuchverlag, München

Lovelock J (1979) Gaia. A new look at life on earth. Oxford University Press, Oxford

Lovelock J (2009) The vanishing face of Gaia-a final warning. Basic Books, New York

Lüttge U (2013) Whole-plant physiology: synergistic emergence rather than modularity. Progr Bot 74:165-190

Lüttge U (2019) Plants: Unitary organisms emerging from integration and self-organization of modules. In: Wegner LH, Lüttge U (eds) Emergence and modularity in life sciences. Springer Nature, Cham, pp 171-193

Lüttge U, Scarano FR (2019) Emergence and sustainment of humankind on earth: the categorical imperative. In: Wegner LH, Lüttge U (eds) Emergence and modularity in life sciences. Springer Nature, Cham, pp 235-254

Lüttge U, Souza G (2019) The golden section and beauty in nature. The perfection of symmetry and the charm of asymmetry. Progr Biophys Mol Biol 146:98-103

Lüttge U, Thellier M (2016) Roles of memory and the circadian clock in the ecophysiological performance of plants. Progr Bot 77:73-104

Matyssek R, Lüttge U (2013) The planet holobiont. In: Matyssek R, Lüttge U, Rennenberg H (eds) The alternatives growth and defense: resource allocation at multiple scales in plants. Nova Acta Leopoldina NF 114/391:325-344

Matyssek R, Maruyama S, Boyer JS (1991) Growth-induced water potentials may mobilize internal water for growth. Plant Cell Environ 14:917-923
Molinier J, Ries G, Zipfel C, Hohn B (2006) Transgeneration memory of stress in plants. Nature 442:1046-1049

Netter H (1959) Theoretische Biochemie. Physikalischchemische Grundlagen der Lebensvorgänge. Springer, Berlin

Ninkovic V (2010) Volatile interaction between undamaged plants: a short cut to coexistence. In: Baluška F, Ninkovic V (eds) Plant communication from an ecological perspective. Springer, Berlin, pp 75-86

Pitman MG (1975) Whole plants. In: Baker DA, Hall JL (eds) Ion transport in plant cells and tissues. North Holland Publishing, Amsterdam, pp 267-308

Roux W (1881) Der Kampf der Teile im Organismus. In: Engelmann (ed) Leipzig 1881

Saze H (2008) Epigenetic memory transmission through mitosis and meiosis in plants. Semin Cell Dev Biol 19:527-536

Scherer S (2017) Denkvoraussetzungen und weltanschauliche Überzeugungen in der Biologie. In: Lüke U, Souvignier G (eds) Wie objektiv ist Wissenschaft? Wiss Buchges, Darmstadt, pp 45-80

Schmidt JC (2019) Is there anything new under the sun? Instability as the core of emergence. In: Wegner LH, Lüttge U (eds) Emergence and modularity in life sciences. Springer Nature, Cham, pp 3-36

Sutcliffe JF (1976) Regulation in the whole plant, vol 2B, Encyclopedia of plant physiology. Springer, Berlin, pp 394-417

Sutcliffe JF (1976b) Regulation of ion transport in the whole plant. Perspectives in experimental biology. In: Sunderland N (ed) Botany, vol II. Pergamon Press, Oxford, p 542

Tang A-C, Boyer JS (2003) Root pressurization affects growthinduced water potentials and growth in dehydrated maize plants. J Exp Bot 54:2479-2488

Tanner W, Grünes R, Kandler O (1970) Spezifität und Turnover des induzierbaren Hexose-Aufnahmesystems von Chlorella. Z Pflanzenphysiol 62:376-386

Thellier M (2011) A half-century adventure in the dynamics of living systems. Progr Bot 73:3-53

Thellier M (2015) Les plantes ont-elles une mémoire. Editions Quæ, Versailles

Thellier M (2017a) Haben Pflanzen ein Gedächtnis? Springer Nature, Berlin

Thellier M (2017b) Plant responses to environmental stimuli. The role of specific forms of plant memory. Springer, Dordrecht

Thellier M, Lüttge U (2013) Plant memory: a tentative model. Plant Biol 15:1-12

Thellier M, Desbiez MO, Champagnat P, Kergosien Y (1982) Do memory processes also occur in plants? Physiol Plant 56:281-284

Thellier M, Demongeot J, Norris V, Guespin J, Ripoll C, Thomas R (2004) A logical (discrete) formulation for the storage and recall of environmental signals in plants. Plant Biol 6:590-597

Thellier M, Ripoll C, Norris V (2013) Memory processes in the control of plant growth and metabolism. Nova Acta Leopoldina NF 114(391):21-41

von Weizsäcker V (1954) Am Anfang schuf Gott Himmel und Erde, 5th edn. Vandenhoeck and Ruprecht, Göttingen

Wegner LH (2019) Modularity versus emergence: How to cope with complexity in whole-plant physiology. In: Wegner 
LH, Lüttge U (eds) Emergence and modularity in life sciences. Springer Nature, Cham, pp 75-95

Wegner LH, Hao Z (2020) A quantitative approach relating emergent features of complex traits to protein expression. Progr Biophys Mol Biol. https://doi.org/10.1016/j. pbiomolbio.2020.10.002

Wolf O, Jeschke WD (1987) Modeling of sodium and potassium flows via phloem and xylem in the shoot of salt-stressed barley. J Plant Physiol 128:371-386 zu Castell W, Lüttge U, Matyssek R (2019) Gaia-a holobiontlike system emerging from interaction. In: Wegner LH, Lüttge U (eds) Emergence and modularity in life sciences. Springer Nature, Cham, pp 255-279

Publisher's Note Springer Nature remains neutral with regard to jurisdictional claims in published maps and institutional affiliations. 